\title{
Stereotactic body radiation therapy for post-pulmonary lobectomy isolated lung metastasis of thoracic tumor: survival and side effects
}

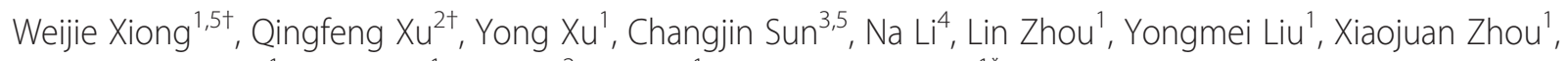
Yongsheng Wang ${ }^{1}$, Jin Wang ${ }^{1}$, Sen Bai ${ }^{2}$, You Lu' ${ }^{1}$ and Youling Gong ${ }^{1 *}$

\begin{abstract}
Background: Stereotactic body radiation therapy (SBRT) has emerged as an alternative treatment for patients with early stage non-small cell lung cancer (NSCLC) or metastatic pulmonary tumors. However, for isolated lung metastasis (ILM) of thoracic malignances after pulmonary lobectomy, reported outcomes of SBRT have been limited. This study evaluates the role of SBRT in the treatment of such patients.

Methods: A retrospective search of the SBRT database was conducted in three hospitals. The parameters analyzed in the treated patients were local control, progression-free survival (PFS), overall survival (OS), and the treatment-related side-effects.

Results: In total, 23 patients with single ILM after pulmonary lobectomy treated with SBRT were identified and the median follow-up time was 14 months (range: 6.0-47.0 months). Local recurrences were observed in two patients during follow-up and the 1-year local control rate was $91.3 \%$. Median PFS and OS for the studied cohort were 10.0 months [95\% confidence interval (Cl) 5.1-14.9 months] and 21.0 months ( $95 \%$ Cl 11.4-30.6 months), respectively. Acute radiation pneumonitis (RP) of grade 2 or worse was observed in five (21.7\%) and three (13.0\%) patients, respectively. Other treatment-related toxicities included chest wall pain in one patient (4.3\%) and acute esophagitis in two patients (8.7\%). By Pearson correlation analysis, the planning target volume (PTV) volume and the volume of the ipsilateral lung exposed to a minimum dose of $5 \mathrm{~Gy}\left(\mathrm{IpV} \mathrm{V}_{5}\right)$ were significantly related to the acute RP of grade 2 or worse in present study $(p<0.05)$. The optimal thresholds of the PTV and IpV $V_{5}$ to predict RP of acute grade 2 or worse RP were $59 \mathrm{~cm}^{3}$ and $51 \%$ respectively, according to the receiver-operating characteristics curve analysis, with sensitivity/specificity of $75.0 \% / 80.0 \%$ and $62.5 \% / 80.0 \%$.
\end{abstract}

Conclusions: SBRT for post-lobectomy ILM was effective and well tolerated. The major reason for disease progression was distant failure but not local recurrence. The PTV and IpV 5 are potential predictors of acute RP of grade 2 or higher and should be considered in treatment planning for such patients.

Keywords: Stereotactic body radiation therapy, Thoracic tumor, Post-lobectomy isolated lung metastasis, Clinical outcomes

\footnotetext{
* Correspondence: gongyouling@gmail.com

${ }^{\dagger}$ Equal contributors

'Department of Thoracic Oncology and State Key Laboratory of Biotherapy,

Cancer Center, West China Hospital, Sichuan University, Chengdu 610041, PR

China

Full list of author information is available at the end of the article
}

\section{Biomed Central}

(c) 2014 Xiong et al.; licensee BioMed Central Ltd. This is an Open Access article distributed under the terms of the Creative Commons Attribution License (http://creativecommons.org/licenses/by/4.0), which permits unrestricted use, distribution, and reproduction in any medium, provided the original work is properly credited. The Creative Commons Public Domain Dedication waiver (http://creativecommons.org/publicdomain/zero/1.0/) applies to the data made available in this article, unless otherwise stated. 


\section{Background}

Tumor lung metastasis is one of the most common oncologic problems, and affects a large percentage of patients of cancer despite the histology of the primary tumor. In most cases, widespread metastases are observed. But in certain instances, lung metastasis may exist in isolation. Resection of isolated lung metastasis (ILM) has traditionally been practiced using methods, such as thoracotomy and video-assisted thoracoscopic surgery (VATS) [1-5]. Such approaches have been proved to be effective, achieving a median survival of 35 months, and are associated with generally acceptable morbidity and mortality rates [6]. However, such pulmonary operations have been practiced in salvage treatments for colorectal cancer, breast cancer and other types of tumors, and rarely for thoracic tumor after pulmonary lobectomy.

Hypo-fractionated stereotactic body radiation therapy (SBRT) can deliver high, biologically effective doses to the tumors while minimizing the irradiation dose to the surrounding tissues [7]. Over the decades, SBRT has emerged as an alternative treatment for medically inoperable patients with early-stage non-small cell lung cancer (NSCLC), showing a 5-year survival rate of more than $80 \%$ with limited morbidity [8-11]. Even among patients with multiple pulmonary metastases, SBRT has been reported as a safe and effective strategy [12-14]. At present, SBRT is recommended by the National Comprehensive Cancer Network (NCCN) panel as a salvage treatment for patients with ILM [15].

For patients with ILM after pulmonary lobectomy, a few treatment outcomes have been reported to date, including for surgery and SBRT. Therefore, we retrospectively analyzed the clinical outcomes of patients at our institutions with post-lobectomy ILM who were treated with SBRT as a component of their overall treatment regimen.

\section{Methods}

\section{Patients' data}

ILM in this study was defined as a circular shape ${ }^{18} \mathrm{~F}$ fluorodeoxyglucose positron-emission tomography (FDGPET) or computed tomography (CT) imaging, without any lobulated signs of original tumor within 3 years after pneumonectomy. We reviewed the records of 268 consecutive patients treated with SBRT for thoracic tumors between October 2009 and December 2013 at the West China Hospital, Second People's Hospital of Sichuan, and Second Affiliated Hospital of Anhui Medical University. Among these patients we identified 23 who had previously received radical resection of thoracic tumors (including pulmonary lobectomy and systematic lymph node dissection) and who subsequently underwent SBRT to treat the ILM of the ipsilateral or contralateral lung. This retrospective study was carried out with the approval of West China Hospital's ethics committee.

\section{SBRT treatment}

The techniques for patient immobilization and treatment planning have been described in detail in previous reports [16,17]. In brief, all patients were simulated and treated in stereotactic immobilization body frame with an active breathing control (ABC) device. All CT images (3-mm thickness) of the patients were transferred to and registered in the treatment planning system (Pinnacle ${ }^{3}$, Philips Radiation Oncology Systems, Fitchburg, WI, USA). The gross tumor volume (GTV) was contoured as the identifiable tumor on planning $\mathrm{CT}$ in the lung window. The clinical target volume (CTV) enclosed the GTV with a $5-\mathrm{mm}$ margin in all directions. For the planning target volume (PTV), another 5-mm margin was added isotropically to the CTV. The spinal cord, esophagus, bronchus and chest wall were contoured as the organs at-risk (OARs).

Two groups of different doses were given to the PTV, prescribed to the 80 or $90 \%$ isodose lines: for small and peripherally located targets, radiation dose was prescribed as $48 \mathrm{~Gy} / 4$ fractions or $50 \mathrm{~Gy} / 5$ fractions; for targets close proximity to critical structures, radiation dose was prescribed as $56 \mathrm{~Gy} / 7$ fractions (Table 1). All fractions were scheduled as three times per week. The dose-volume constraints used for OARs followed the NCCN guidelines [15] and the recommendations from the Radiation Therapy Oncology Group (RTOG) [18]. Plans were generated with five or seven coplanar beams of 6-MV X-rays.

\section{Treatment assessment and follow-up}

Evaluation of treatment response was carried out according to Response Evaluation Criteria in Solid Tumors (RECIST criteria) based on findings from either FDGPET or CT images [19]. Local recurrence was defined as any re-enlargement of the target if complete response (CR) had not been reached after SBRT or re-appearance of the target if $\mathrm{CR}$ had been reached. Progression was defined as a local recurrence or appearance of new lesions. Follow-up evaluations were started 4 weeks after the date of the last SBRT treatment, and performed every 2-3 months for the first 2 year and every 6 months thereafter.

Toxicities were evaluated and graded according to the National Cancer Institute Common Toxicity Criteria Adverse Event version 3.0 (CTC AE v3.0) [20]. A diagnosis of radiation pneumonitis (RP) was made based on clinical symptoms (including cough, shortness of breath and fever), and radiologic findings in the absence of any other likely cause. 
Table 1 Treatment in present study $(n=23)$

\begin{tabular}{|c|c|}
\hline Stereotactic body radiation therapy & \\
\hline \multicolumn{2}{|l|}{ Irradiation dose delivered } \\
\hline $12 \mathrm{~Gy} \times 4$ fractions three times per week & $11(47.8 \%)$ \\
\hline 10 Gy $\times 5$ fractions three times per week & $9(39.1 \%)$ \\
\hline 8 Gy $\times 7$ fractions three times per week & $3(13.0 \%)$ \\
\hline Active breathing control & $23(100 \%)$ \\
\hline Cone-beam CT guiding & $23(100 \%)$ \\
\hline \multicolumn{2}{|l|}{ PTV volume $\left(\mathrm{cm}^{3}\right)$} \\
\hline Median & 48.4 \\
\hline Range & $26.0-110.2$ \\
\hline \multicolumn{2}{|l|}{ Lung volume $\left(\mathrm{cm}^{3}\right)$} \\
\hline Total lung (median) & 2301.4 \\
\hline (range) & 1983.4-2950.5 \\
\hline Contralateral lung (median) & 1373.4 \\
\hline (range) & $1255.8-1712.3$ \\
\hline Ipsilateral lung (median) & 942.2 \\
\hline (range) & 786.8-1233.4 \\
\hline \multicolumn{2}{|l|}{ Systematic treatment } \\
\hline \multicolumn{2}{|l|}{ Chemotherapy } \\
\hline Concurrent chemotherapy & $1(4.3 \%)$ \\
\hline Sequential chemotherapy & $14(60.9 \%)$ \\
\hline Tyrosine kinase inhibitor $^{a}$ & $3(13.0 \%)$ \\
\hline None & $5(21.7 \%)$ \\
\hline
\end{tabular}

$a_{\text {: Erlotinib or Gefetinib. }}$

\section{Statistical methods}

Statistical analyses were performed using SPSS software (version 17.0). The timing of recurrence or distant metastasis was recorded as the time at which the first image (FDG-PET or CT) showed abnormalities. Progression-free survival (PFS) time was measured from the date of the last SBRT to the date of the disease progression, and the overall survival (OS) time was considered from the last date of treatment to the date of analysis or date of loss from follow-up for patients alive. Patients without local recurrence or progression who discontinued the follow-up for any reason were censored on the date on the last tumor assessment.

The rates of PFS and OS curves were calculated using Kaplan-Meier analysis. Spearman's rank correlation analysis was applied to determine correlations between the dose-volume histogram (DVH) -based parameters and the incidence of RP. Receiver-operating characteristics (ROC) curve analysis for each parameter was also applied to select the most relevant threshold to predict RP for grade 2 or higher. The optimal threshold for each DVH-based parameter was defined as the point yielding the minimal value for $(1 \text {-sensitivity })^{2}+(1 \text {-specificity })^{2}$, according to the report from Akobeng [21]. A value of $p<0.05$ was considered to have statistical significance.

\section{Results}

The basic and clinical characteristics of the studied population are summarized in Table 2. The median age of the

Table 2 Basic and clinical characteristics of the patients in present study $(\mathbf{n}=\mathbf{2 3})$

\begin{tabular}{lc}
\hline Characteristics & $\begin{array}{c}\text { Number of patients } \\
\text { (\%) }\end{array}$ \\
\hline Age (years) & $58(45-74)$ \\
Median (range) & \\
Gender & $17(73.9) / 6(26.1)$ \\
$\quad$ Male/Female & \\
ECOG ${ }^{\boldsymbol{a}}$ performance status & $21(91.3)$ \\
$0-1$ & $2(8.7)$ \\
2 & \\
Pathology of the primary tumor & $10(43.5)$ \\
Squamous-cell lung cancer & $10(43.5)$ \\
Non-squamous cell lung cancer & $2(8.7)$ \\
Sarcomatoid carcinoma & $1(4.3)$ \\
Small cell lung cancer & \\
Surgical method & $9(39.1)$ \\
Right upper lung lobectomy & $3(13.0)$ \\
Right lower lung lobectomy & $5(21.7)$ \\
Left upper lung lobectomy & $4(17.4)$ \\
Left lower lung lobectomy & $2(8.7)$ \\
Left pneumonectomy & \\
$T$ staging after surgery & \\
T1/T2/T3/T4 & $(34.8) / 1(4.3)$ \\
&
\end{tabular}

\section{$N$ staging after surgery ${ }^{b}$}

NO/N1/N2

Tumor stage after surgery ${ }^{b}$

$$
\text { I }
$$

Time from surgery to lung metastasis (months)

Median (range)

\section{Sites of lung metastasis}

Contralateral lung of the primary tumor

Ipsilateral lung of the primary tumor

$11(47.8)$

\section{Follow-up time since diagnosis of lung} metastasis (months)

Median (range) $14.0(6.0-47.0)$

${ }^{a}$ : Eastern Cooperative Oncology Group; ${ }^{b}:$ staging system, $6^{\text {th }}$ edition, American Joint Committee on Cancer, 2002. 
patients was 58 years (range: 45-74 years); most of them were male and with Eastern Cooperative Oncology Group (ECOG) performance status score 0-1 (21/23; 91.3\%). Of the 23 patients, 10 (43.5\%) had squamous-cell lung cancer, 10 had non-squamous cell lung cancer and three (13\%) patients had, other pathological types respectively. According to our records, 9, 3, 5 and 4 patients had received resection of right upper lobe, right lower lobe, left upper lobe, and left lower lobe respectively. Two patients had undergone left pneumonectomy. The pathologic stage confirmed with surgery(Staging system, American Joint Committee on Cancer, $6^{\text {th }}$ edition) [22] in the present study were $6(26.1 \%)$ stage I, $9(39.1 \%)$ stage II, and 8 (34.8\%) stage III respectively. The ILMs of the contralateral (12 patients) and ipsilateral (11 patients) lung were observed. The median time from surgery to ILMs and followup time was 16.0 months (range: 4.0-75.0 months, only 1 patient was diagnosed with ILM 75 months after pneumonectomy) and 14.0 months (range: 6.0-47.0 months), respectively.

\section{Treatment}

In the present study, 11 (47.8\%), nine (39.1\%) and three (13.0\%) patients had received the prescription dose of 48 Gy (4 fractions), 50 Gy (5 fractions) and 56 Gy (7 fractions), respectively (Table 1 ). The median PTV was $48.4 \mathrm{~cm}^{3}$ (range: 26.0-110.2 $\mathrm{cm}^{3}$ ). The median lung volume was $2301.4 \mathrm{~cm}^{3}$ (range: 1983.4-2950.5 $\mathrm{cm}^{3}$ ). All patients underwent $\mathrm{ABC}$ and cone-beam CT guidance during treatment. Fourteen (60.9\%) and 1(4.3\%) patients received sequential and concurrent chemotherapy respectively, as parts of the treatment strategies. Three patients (13.0\%) received tyrosine kinase inhibitors as the systematic treatment, and only five (21.7\%) patients had not received systematic therapy.

\section{Local control and survival}

Follow-up studies continued until December 2013, with no patients lost to follow-up. Local recurrences were observed in two patients during follow-up, and the 1year local control rate (LCR) was 91.3\%. As Figure 1 shows, the median PFS and OS for the studied cohort were 10.0 months [95\% confidence interval (CI) 5.114.9 months] and 21.0 months (95\% CI 11.4-30.6 months), respectively.

Figure 2 shows a patient with an ILM on the right pulmonary lobe, whose primary tumor was sarcomatoid carcinoma and who had received left pneumonectomy. The irradiation dose delivered was 10 Gy per fraction for five fractions. Figure 2 also shows a CR achieved 9 months after SBRT treatment (Figure 2c, d). Only light patchy shadows near the chest wall were observed as side effects of treatment.

\section{Treatment-related toxicities}

All patients were evaluated for treatment-related toxicities (Table 3). The SBRT for ILM after pulmonary lobectomy was judged to be tolerable. The most common toxicity was cough $(60.9 \%, 14$ patients). Coughs of grade 2 , 3, and 4 were recorded in four $(17.4 \%)$, two $(8.7 \%)$ and one $(4.3 \%)$ patients, respectively. Other toxicities included shortness of breath (8.7\%, two patients), acute esophagitis (8.7\%, two patients) and chest wall pain (4.3\%, one patient). No grade 5 toxicity was recorded.

Figure 3 shows a patient with ILM of small-cell lung cancer on the right upper lobe after right lower lobectomy. The prescription dose was $10 \mathrm{~Gy}$ per fraction for

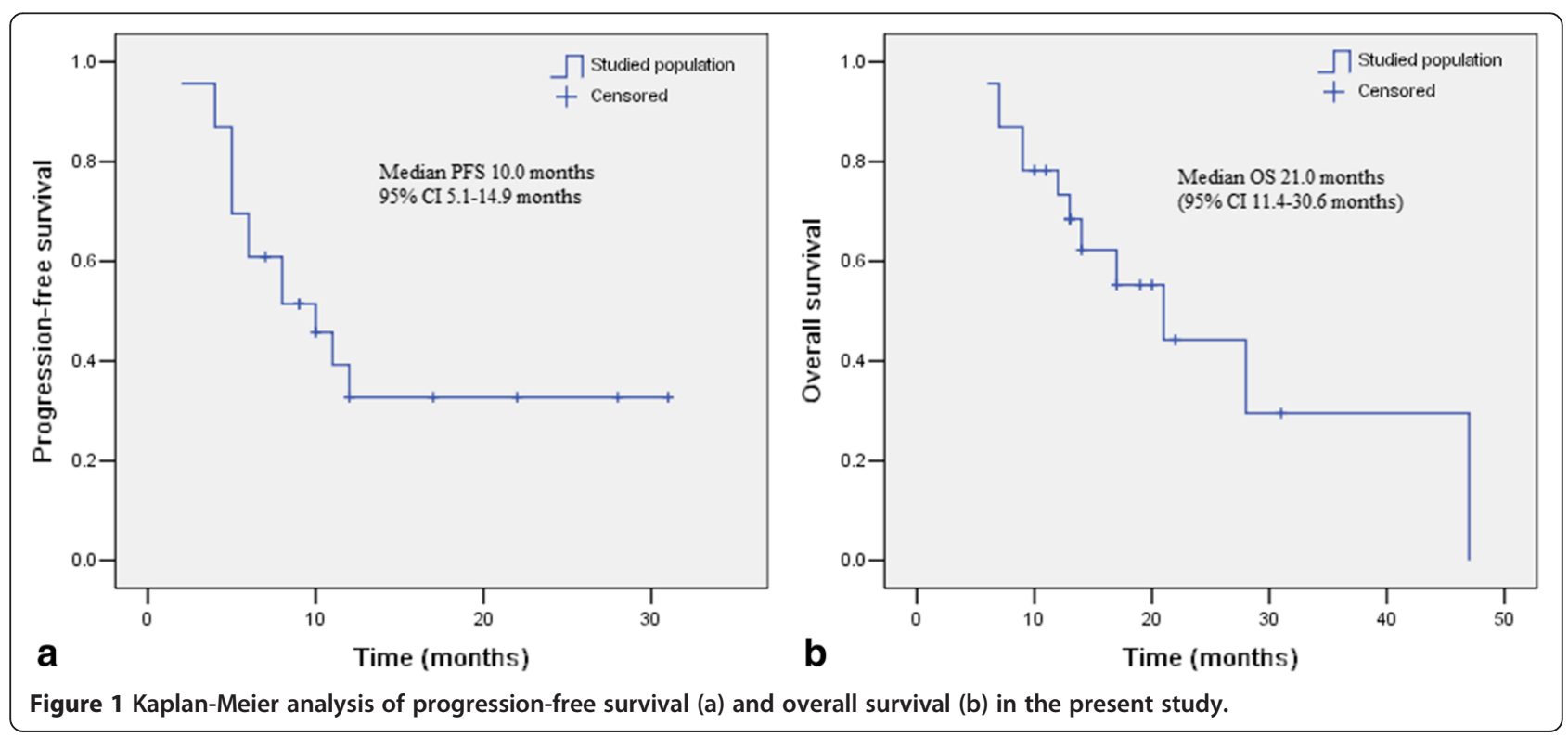




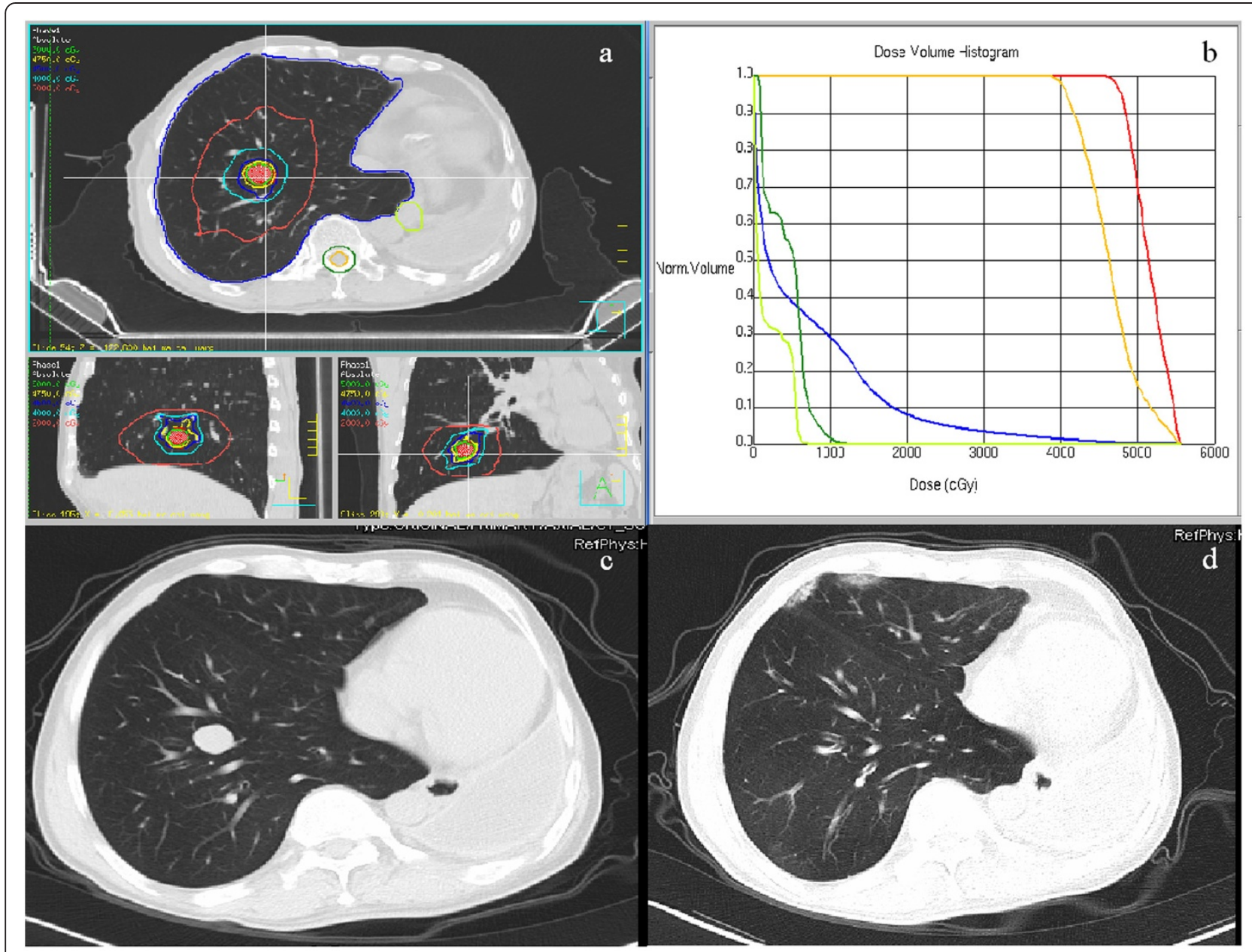

Figure 2 Complete response after SBRT in the representative patient. (a: irradiation isodose curves of the SBRT plan 50 Gy in 5 fractions; b: dose-volume histogram of the SBRT plan; c: CT image before SBRT; d: CT image 9 months after SBRT).

five fractions. The volume of lung exposed to a minimum dose of 20 Gy $\left(\mathrm{V}_{20}\right)$ and $\mathrm{V}_{30}$ of total lungs was less than 15 and $10 \%$ respectively. One month after SBRT, the patient experienced severe cough and dyspnea; CT scans showed a stable disease as the response to treatment, and widespread, patchy shadows on both upper

Table 3 The acute $\mathrm{SBRT}^{a}$-related toxicities in present study $(\mathbf{n}=\mathbf{2 3})$

\begin{tabular}{lccccc}
\hline Toxicities $^{b}$ & \multicolumn{5}{c}{ Toxicity grades, $\mathbf{n}(\%)$} \\
\cline { 2 - 7 } & Grade 0 & Grade 1 & Grade 2 & Grade 3 & Grade 4 \\
\hline $\begin{array}{l}\text { Radiation pneumonitis } \\
\text { Cough }\end{array}$ & $9(39.1)$ & $7(30.4)$ & $4(17.4)$ & $2(8.7)$ & $1(4.3)^{c}$ \\
Shortness of breath & $21(91.3)$ & 0 & $1(4.3)$ & 0 & $1(4.3)^{c}$ \\
Other treatment-related toxicities & & & \\
Chest wall pain & $22(95.7)$ & 0 & $1(4.3)$ & 0 & 0 \\
Acute esophagitis & $21(91.3)$ & 0 & $2(8.7)$ & 0 & 0 \\
\hline
\end{tabular}

${ }^{a}$ : stereotactic body radiation therapy; ${ }^{b}$ : according to the Common Toxicity Criteria for Adverse Events, version 3.0; ${ }^{c}$ : same patient. lobes (grade 4 RP). After steroid therapy for 6 weeks, the patient recovered.

\section{Correlations between lung parameters and incidence of RP}

Table 4 summarizes the correlations between the DVHbased lung parameters and acute RP of grade 2or higher. The incidence of acute RP of grade $\geq 2$ was significantly associated with the PTV (mean: 59.0vs. $45.0 \mathrm{~cm}^{3}, p=$ 0.039). Another possible predictive parameter was the $V_{5}$ of the ipsilateral lungs $\left(\mathrm{IpV}_{5}\right)$ (mean: 51.0 vs. $44.0 \%, p=$ $0.034)$. Other lung parameters did not significantly correlate with the incidence of acute RP of grade 2 or higher.

By ROC analysis, the areas under curve were 0.758 $(p=0.045)$ and $0.700(p=0.121)$ for PTV and $\mathrm{IpV}_{5}$, respectively (Figure 4). Additionally, the optimal values to predict acute RP of grade 2 or higher were $59 \mathrm{~cm}^{3}$ (for PTV) with sensitivity of $75 \%$ and specificity of $80.0 \%$ 


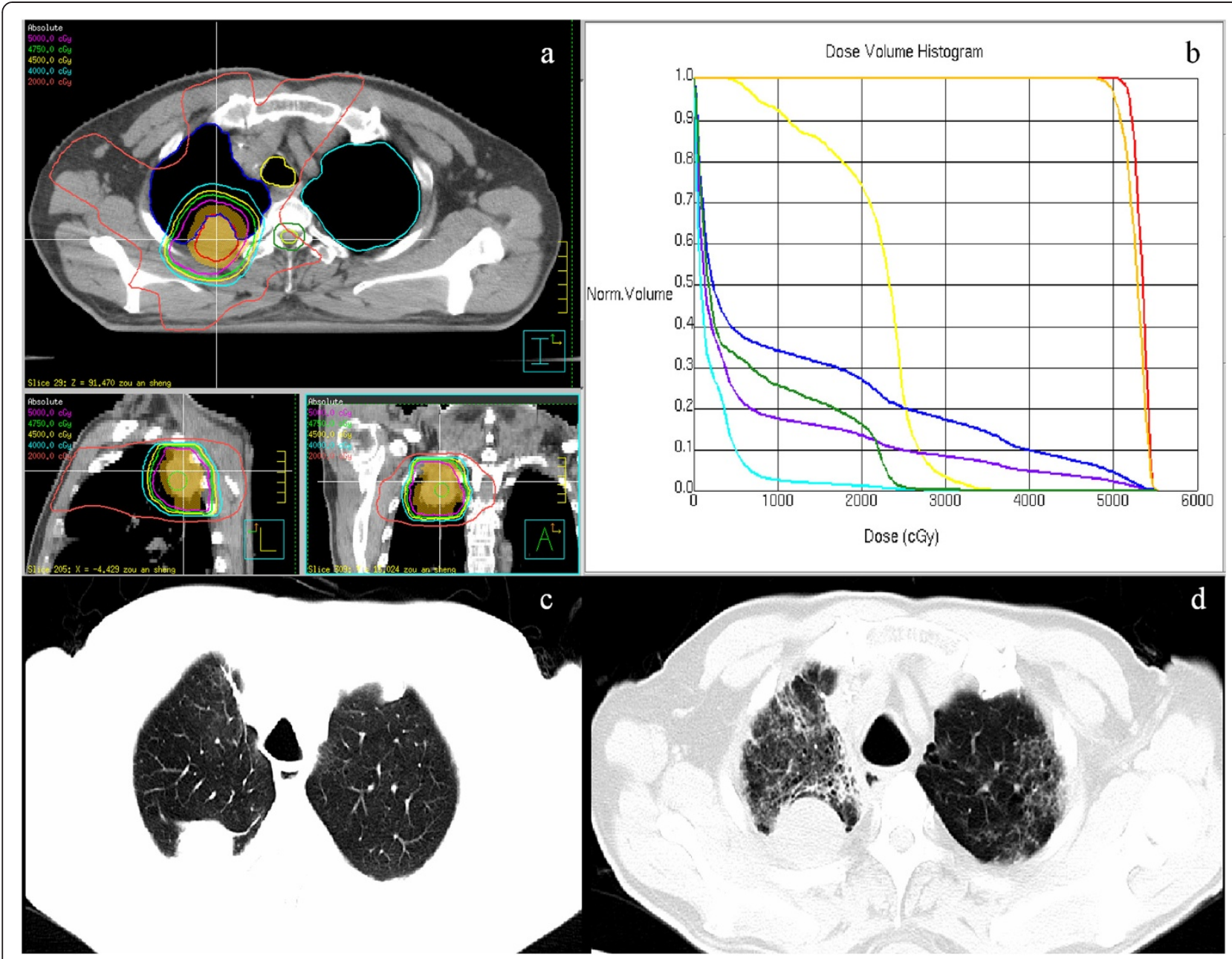

Figure 3 Representative patient who developed grade 4 radiation pneumonitis. (a: irradiation isodose curves of the SBRT plan 50 Gy in 5 fractions; $\mathbf{b}$ : dose-volume histogram of the SBRT plan, arrow pointing the curve of the total lung; $\mathbf{c}$ : CT image before SBRT; $\mathbf{d}$ : CT image one month after SBRT).

(Table 5). The optimal value for $\mathrm{IpV}_{5}$ was $51 \%$, with sensitivity/specificity of $62.5 \%$ and $80.0 \%$, respectively.

\section{Discussion}

The treatment of cancer patients with ILM is a common clinical problem. SBRT is an appealing treatment option, but little is known about its use in the post-lobectomy setting. Our initial experience of using hypo-fractionated SBRT for ILM after pulmonary lobectomy is presented here for the first time.

The 1-year LCR was $91.3 \%$ for all patients in the present study, the median PFS and OS were 10.0 and 21.0 months, respectively. Our data are consistent with those of other reports on SBRT for metastatic lung cancer [23-25], especially the report from Norihisa et al. whose prescription dose was 48-60 Gy/4-5 fractions and LCR 90.0\% [25]. These clinical outcomes were comparable with those achieved by surgical metastasectomy [6]. In 2009, Rusthoven et al. reported a prospective multi-institutional phase
I/II trial of SBRT for metastatic lung tumor, and reported actuarial LCRs at 1 and 2 years after SBRT of 100 and 96\%, respectively. After a median follow-up of 15.4 months, a median survival of 19 months was achieved using a prescription dose of 48-60 Gy in three fractions [26]. Our data also confirmed that the main pattern of failure after SBRT was distant metastasis, as was concluded in a systematic review by Chi et al. [27].

A few studies have evaluated the outcomes of SBRT among patients after pneumonectomy [28-30]. Authors from the VU University Medical Center in the Netherlands reported on 15 patients with a second primary lung cancer who received SBRT after pneumonectomy in 2009 [28]. After a median follow-up time of 16.5 months, no local failures were observed and the 1-year actuarial disease-free survival rate was $92 \%$. In 2013, the same investigatorsy updated their data and compared the outcomes between SBRT, hypo-fractionated radiotherapy, and conventional radiotherapy among such patients [29]. In this paper, they 
Table 4 Correlations between the $\mathrm{DVH}^{a}$-based parameters and acute grade $\geq \mathbf{2} \mathbf{R P}^{b}$ in present study $(n=23)$

\begin{tabular}{|c|c|c|c|}
\hline & $\begin{array}{c}\text { Grade } \geq 2 \text { RIP }(n=8) \\
\text { mean } \pm \text { SD }\end{array}$ & $\begin{array}{c}\text { Grade } 0-1 \text { RIP }(n=15) \\
\text { mean } \pm \text { SD }\end{array}$ & $p$ value \\
\hline \multicolumn{4}{|l|}{ Total Lungs } \\
\hline$V_{5}(\%)^{c}$ & $36.0 \pm 6.0$ & $35.0 \pm 4.0$ & 0.141 \\
\hline$V_{10}(\%)^{c}$ & $16.0 \pm 4.0$ & $14.0 \pm 2.0$ & 0.125 \\
\hline$V_{20}(\%)^{c}$ & $4.8 \pm 2.0$ & $4.4 \pm 1.2$ & 0.696 \\
\hline$V_{30}(\%)^{c}$ & $2.0 \pm 1.0$ & $2.0 \pm 1.0$ & 0.990 \\
\hline $\operatorname{MLD}(G y){ }^{d}$ & $3.8 \pm 1.6$ & $3.7 \pm 1.3$ & 0.077 \\
\hline \multicolumn{4}{|l|}{ Contralateral lungs } \\
\hline$V_{5}(\%)$ & $26.0 \pm 7.0$ & $25.0 \pm 9.0$ & 0.421 \\
\hline$V_{10}(\%)$ & $18.0 \pm 7.0$ & $16.0 \pm 9.0$ & 0.277 \\
\hline$V_{20}(\%)$ & $3.2 \pm 1.1$ & $2.4 \pm 0.9$ & 0.210 \\
\hline$V_{30}(\%)$ & $1.6 \pm 0.5$ & $1.6 \pm 0.6$ & 0.992 \\
\hline MLD (Gy) & $2.8 \pm 0.6$ & $2.6 \pm 0.2$ & 0.483 \\
\hline \multicolumn{4}{|l|}{ Ipsilateral lungs } \\
\hline$V_{5}(\%)$ & $51.0 \pm 9.1$ & $44.0 \pm 4.0$ & 0.034 \\
\hline$V_{10}(\%)$ & $22.0 \pm 6.0$ & $19.0 \pm 4.0$ & 0.273 \\
\hline$V_{20}(\%)$ & $6.0 \pm 2.8$ & $5.2 \pm 2.2$ & 0.454 \\
\hline$V_{30}(\%)$ & $2.6 \pm 1.0$ & $2.8 \pm 1.1$ & 0.824 \\
\hline MLD (Gy) & $5.9 \pm 1.3$ & $5.7 \pm 1.1$ & 0.290 \\
\hline PTV volume $\left(\mathrm{cm}^{3}\right)$ & $59.0 \pm 9.6$ & $45.0 \pm 9.9$ & 0.039 \\
\hline
\end{tabular}

${ }^{a}$ : dose-volume histogram; ${ }^{b}$ : radiation pneumonitis; ${ }^{c}:$ the percentage of the lung volume that received more than $5,10,20$ and 30 Gy irradiation dose, respectively; ${ }^{d}$ : mean lung dose.
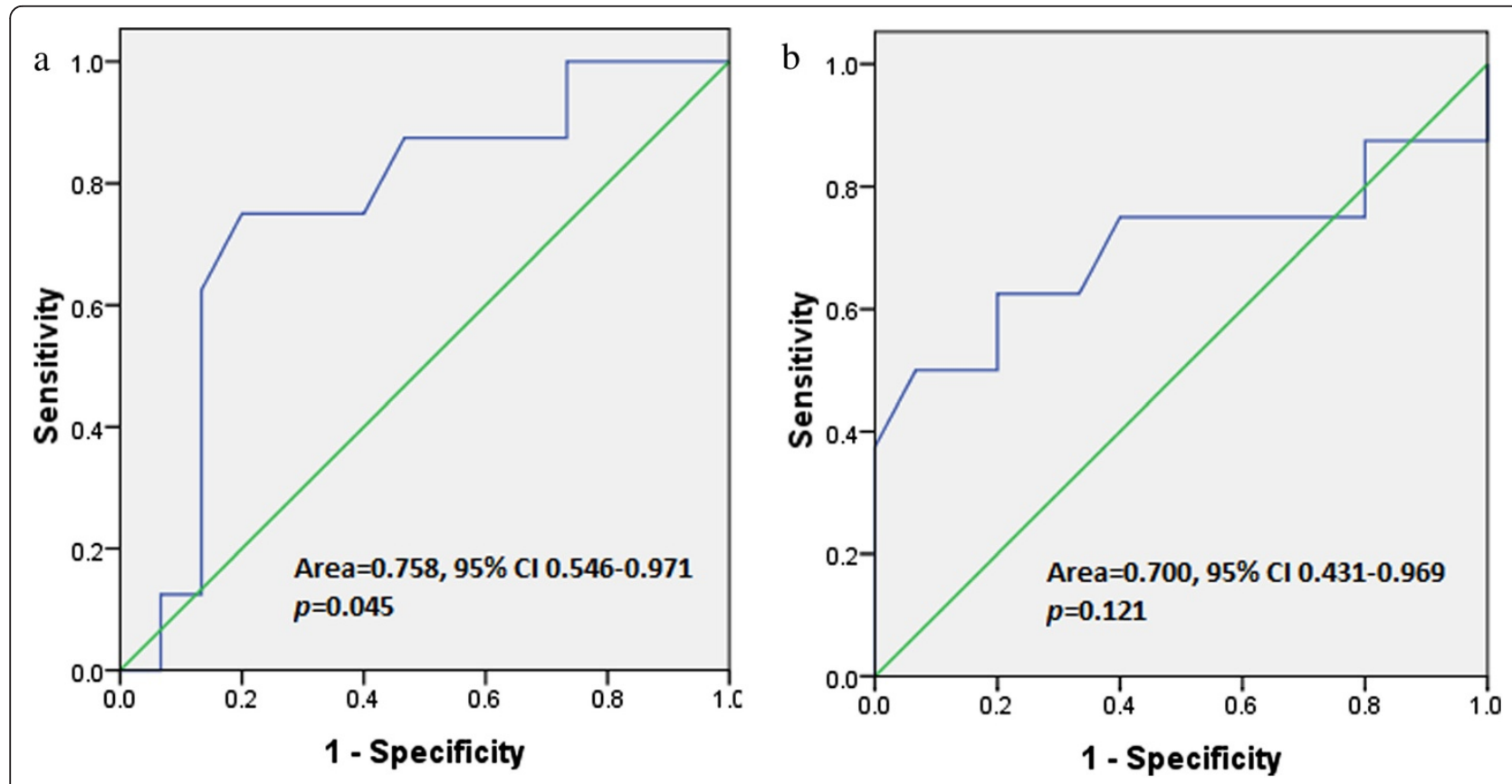

Figure 4 Receiver operating characteristics (ROC) curve analysis in present study. (a: for PTV volume and $\mathbf{b}$ : for $V_{5}$ of the ipsilateral lung). 
Table $5 \mathrm{ROC}^{a}$ curve analysis for $\mathrm{DVH}^{b}$-based parameters related to acute grade $\geq \mathbf{2} \mathrm{RP}^{\mathrm{C}}$ in present study

\begin{tabular}{lccc}
\hline \multicolumn{1}{c}{ Parameters } & \multicolumn{3}{c}{ Optimal threshold } \\
\cline { 2 - 4 } & Value & Sensitivity & Specificity \\
\hline PTV volume $\left(\mathrm{cm}^{3}\right)$ & 59 & $75.0 \%$ & $80.0 \%$ \\
Ipsilateral lung $\mathrm{V}_{5}^{d}(\%)$ & 51 & $62.5 \%$ & $80.0 \%$ \\
\hline
\end{tabular}

${ }^{a}$ : receiver operating characteristic; ${ }^{b}$ : dose-volume histogram; ${ }^{c}$ : radiation pneumonitis; ${ }^{d}$ : the percentage of the ipsilateral lung volume that received more than 5 Gy irradiation dose.

reported a median OS of 39 months during follow-up. Thompson et al. identified 13 patients with newly identified lung malignancy after surgery from 406 patients who received SBRT [30]. The doses delivered were $60 \mathrm{~Gy} / 3$ fractions $(\mathrm{n}=1), 54 \mathrm{~Gy} / 3$ fractions $(\mathrm{n}=1), 48 \mathrm{~Gy} / 4 \mathrm{frac}-$ tions $(\mathrm{n}=7), 60 \mathrm{~Gy} / 8$ fractions $(\mathrm{n}=2)$, and $50 \mathrm{~Gy} / 10$ fractions $(\mathrm{n}=3)$. The Median survival was 29 months, and no local failures were observed. In our cohort, the targets were metastatic tumors; thus, even though the local control rate was similar to that the reported in the aforementioned studies discussed above, the OS (median 21 months) among our patients was shorter than in those patients with newly diagnosed lung cancer.

The SBRT treatment was well tolerated in our patient population. The most common toxicity was cough (60.9\%), and acute RP of grade 3 or worse was observed in three patients $(13.0 \%)$. Other treatment-related toxicities included dyspnea, chest wall pain, and acute esophagitis. These findings are consistent with the reports evaluating SBRT in newly identified lung cancer after pneumonectomy $[28,30]$ and in medically inoperable or operable NSCLC [26,31-37]. In the post-pneumonectomy settings, Haasbeek et al. reported that only two 2 patients experienced toxicity of grade 3 or higher toxicity [28]. In a report by Thompson et al., two2 patients in a 13-patient cohort had grade 3 RP [30]. For medically inoperable or operable NSCLC, in the RTOG trial 0236, with a prescription dose of 54 Gy in three fractions, treatment-related grade 3 and 4 toxicities of pulmonary or upper respiratory tract were observed in 14.5 and $1.8 \%$ of patients, respectively [31]. In a phase II study of SBRT, Baumann et al. reported that grade 3 pulmonary toxicities were seen in 11.8 and $12.5 \%$ of patients in the cardio-vascular disease group and chronic obstructive pulmonary disease group, respectively [32]. In a study from Japan (JCOG 0403), Nagata et al. reported grade 3 toxicity in $6.2 \%$ of their patients who received SBRT treatment [33]. For metastatic lung cancer, Rusthoven et al. reported that grade 2 RP occurred in only one patient $(2.6 \%)$ in their multi-institutional phase I/II trial [26]. The investigators suggested that the low rate of pneumonitis observed might have contributed to the dose constraint used $\left(\mathrm{V}_{15}<35 \%\right)$ in their patient population. However this needs to be confirmed in a larger cohort of patients because in our study, one patient developed grade $4 \mathrm{RP}$, and the $\mathrm{V}_{15}$ was less than $17 \%$ according to the DVH analysis.

Several studies have evaluated the potential value of the DVH-based lung parameters in predicting acute "symptomatic" RP after SBRT [34-38]. The RP rates were reported within a range of $9.4 \%$ to $28.0 \%$, and the possible predictive factors for RP differed among these studies. In 2007, Yamashita et al. reported that 29\% of their patients had developed grade 2 or worse RP after SBRT (48 Gy in four fractions), and that the conformity index was the only factor associated with incidence of RP [34]. Ricardi et al. observed a good correlation between mean lung dose (MLD) and grade 2-3 pulmonary toxicity $(p=0.008$, odds ratio 1.5$)$ in a 60 -patients cohort after SBRT of 15 Gy per fraction $\times 3$ fractions [35]. Moreover, reports by Borst et al., Guckenberger et al. and Barriger et al. indicated that MLD (ipsilateral or total lung) was correlated with incidences of symptomatic RP after pulmonary SBRT [36-38]. Onestudy indicated that $\mathrm{V}_{5}$ of total lung $>37 \%$ and $\mathrm{V}_{5}$ of contralateral lung $>26 \%$ were suitable predictors of pneumonitis in a cohort of patients treated with SBRT [39]. Additionally, Guckenberger et al. reported that the $\mathrm{V}_{2.5}-\mathrm{V}_{50}$ were correlated with incidences of RP with a continuous decrease of the goodness of fit for higher doses [37]. In a Japanese study, Matsuo et al. concluded that the symptomatic RP rate was significantly lower in the group with PTV < $37.7 \mathrm{~mL}$ compared with the group with larger PTV (11.1 vs. $34.5 \%, p=0.02$ ) [40]. In the present study, we also identified two factors that might significantly be associated with RP of grade 3 or worse after SBRT in the post-lobectomy situation: PTV and $\mathrm{IpV}_{5}$. Like other parameters already mentioned, the value of these two factors as the thresholds in SBRT for ILM warrants further clinical investigations.

To the best of our knowledge, there is little information regarding the correlation between various DVH-based factors and lung toxicity in radiotherapy among patients after pulmonary lobectomy. Uno et al. reported that higher in $\mathrm{V}_{13 / 20}$ and MLD values could be a surrogate for RP in NSCLC patients after lobectomy [41]. While the treatment was concurrent chemo-radiotherapy for recurrent NSCLC, these parameters could not be easily followed in an SBRT setting.

Some limitations of the present study justify mention. First, this analysis was retrospective and the number of patients evaluated was limited, thus leading to a bias of selection. Second, being a multicenter study, there was no central data review, and the determination of RP can be subjective and challenging. Third, there is an obvious difference between the RTOG system, CTC AE v2.0, and CTC AE v3.0 regarding steroid use for RP. Tucker et al. reported 442 patients who received definitive radiotherapy using these three toxicity grading systems: RP of 
grade 2 or worse was observed in 29, 25, and $44 \%$ of patients according to RTOG, CTC AE v2.0 and CTC AE v3.0, respectively [42]. Therefore, attention should be paid to the toxicity grading systems when interpreting the results discussed herein.

\section{Conclusions}

In conclusion, our results indicate that SBRT is a promising tool for the salvage treatment of ILM in patients who had previously received pulmonary lobectomy. PTV and $\mathrm{IpV}_{5}$ are possible predictive factors for the development of symptomatic RP. Prospective studies are needed to verify these findings.

\section{Competing interests}

The authors declare that they have no competing interests.

\section{Authors' contributions}

WX and QX contributed equally in collection and analysis of data and drafting the manuscript; YX, CS and NL contributed in collection and analysis of data; LZ, YL, YW, JW, SB and YL provided the critical revision of the manuscript and the administrative support; YG provided the conception of this study and the final approval of the version to be published. And all authors read and approved the final manuscript.

\section{Acknowledgement}

This work was partly supported by the grant from Sichuan Provincial Science and Technology Founding (2014SZ0148).

\section{Author details}

1 Department of Thoracic Oncology and State Key Laboratory of Biotherapy, Cancer Center, West China Hospital, Sichuan University, Chengdu 610041, PR China. ${ }^{2}$ Radiation Physics Center, Cancer Center, West China Hospital, Sichuan University, Chengdu 610041, PR China. ${ }^{3}$ Department of Radiation Oncology, The Second People's Hospital of Sichuan Province, Chengdu 610031, PR China. ${ }^{4}$ Department of Oncology, Second Affiliated Hospital of Anhui Medical University, Hefei 230601, PR China. ${ }^{5}$ Current addresses: Chengdu Fifth People's Hospital and Chengdu Third People's Hospital, Chengdu, China.

Received: 7 April 2014 Accepted: 24 September 2014

Published: 26 September 2014

\section{References}

1. Rusch W: Surgical techniques for pulmonary metastasectomy. Semin Thorac Cardiovasc Surg 2002, 14:4-9.

2. Mutsaerts EL, Zoetmulder FA, Meijer S, Baas P, Hart AA, Rutgers EJ: Outcome of thoracoscopic pulmonary metastasectomy evaluated by confirmatory thoracotomy. Ann Thorac Surg 2001, 72:230-233.

3. Mutsaerts EL, Zoetmulder FA, Meijer S, Baas P, Hart AA, Rutgers EJ: Long term survival of thoracoscopic metastasectomy vs metastasectomy by thoracotomy in patients with a solitary pulmonary lesion. Eur J Surg Oncol 2002, 28:864-868.

4. Horan TA, Santiago FF, Araujo LM: The benefit of pulmonary metastectomy for bone and soft tissue sarcomas. Int Surg 2000, 85:185-189.

5. Nakajima J, Takamoto S, Tanaka M, Takeuchi E, Murakawa T, Fukami T: Thoracoscopic surgery and conventional open thoracotomy in metastatic lung cancer. Surg Endosc 2001, 15:849-853.

6. Pastorino U, Buyse $M$, Friedel $G$, Ginsberg $R$, Girard $P$, Goldstraw $P$, Johnston M, McCormack P, Pass H, Putnam JB Jr: For The International Registry of Lung Metastasis: Long-term results of lung metastasectomy: prognostic analyses based on 5206 cases. J Thorac Cardiovasc Surg 1997, 113:37-49.

7. Timmerman RD, Kavanagh BD, Cho LC, Papiez L, Xing L: Stereotactic body radiation therapy in multiple organ sites. J Clin Oncol 2007, 25:947-952.
8. Blomgren H, Lax I, Naslund I, Svanstrom R: Stereotactic high dose fraction radiation therapy of extracranial tumors using an accelerator. Clinical experience of the first thirty-one patients. Acta Oncol 1995, 34:861-870.

9. Nagata Y, Negoro Y, Aoki T, Mizowaki T, Takayama K, Kokubo M, Araki N, Mitsumori M, Sasai K, Shibamoto Y, Koga S, Yano S, Hiraoka M: Clinical outcomes of 3D conformal hypofractionated single high-dose radiotherapy for one or two lung tumors using a stereotactic body frame. Int J Radiat Oncol Biol Phys 2002, 52:1041-1046.

10. Onishi H, Araki T, Shirato H, Nagata $Y$, Hiraoka M, Gomi K, Yamashita T, Niibe Y, Karasawa K, Hayakawa K, Takai Y, Kimura T, Hirokawa Y, Takeda A, Ouchi A, Hareyama M, Kokubo M, Hara R, Itami J, Yamada K: Stereotactic hypofractionated high-dose irradiation for stage I non-small cell lung carcinoma: clinical outcomes in 245 subjects in a Japanese multiinstitutional study. Canc 2004, 101:1623-1631.

11. Timmerman R, Papiez L, McGarry R, Likes L, DesRosiers C, Frost S, Williams $\mathrm{M}$ : Extracranial stereotactic radioablation: results of a phase I study in medically inoperable stage I non-small cell lung cancer. Chest 2003, 124:1946-1955.

12. Okunieff P, Petersen AL, Philip A, Milano MT, Katz AW, Boros L, Schell MC: Stereotactic body radiation therapy (SBRT) for lung metastases. Acta Oncol 2006, 45:808-817.

13. Ricardi U, Filippi AR, Guarneri A, Ragona R, Mantovani C, Giglioli F, Botticella A, Ciammella P, Iftode C, Buffoni L, Ruffini E, Scagliotti GV: Stereotactic body radiation therapy for lung metastases. Lung Cancer 2012, 75:77-81.

14. Milano MT, Philip A, Okunieff P: Analysis of patients with oligometastases undergoing two or more curative-intent stereotactic radiotherapy courses. Int J Radiat Oncol Biol Phys 2009, 73:832-837.

15. Non-small cell lung cancer: National Comprehensive Cancer Network, Guidelines Version 1; 2014. www.nccn.org.

16. Chen YS, Guo WH, Lu Y, Zou BW: Dose-individualized stereotactic body radiotherapy for T1-3 N0 non-small cell lung cancer: long-term results and efficacy of adjuvant chemotherapy. Radiother Oncol 2008, 88:351-358.

17. Shen $Y L$, Zhang $H$, Wang J, Zhong RM, Jiang XQ, Xu QF, Wang X, Bai S, XU $F$ : Hypofractionated radiotherapy for lung tumors with online cone beam CT guidance and active breathing control. Radiat Oncol 2010, 51:9.

18. Lo SS, Fakiris AJ, Papiez L, Abdulrahman R, McGarry RC, Henderson MA Forquer JA, Hoopes D, Timmerman RD: Stereotactic body radiation therapy for early-stage non-small-cell lung cancer. Expert Rev Anticancer Ther 2008, 8:87-98.

19. Therasse P, Arbuck SG, Eisenhauer EA, Wanders J, Kaplan RS, Rubinstein L, Verweij J, Van Glabbeke M, van Oosterom AT, Christian MC, Gwyther SG: New guidelines to evaluate the response to treatment in solid tumors. European Organization for Research and Treatment of Cancer, National Cancer Institute of the United States, National Cancer Institute of Canada. J Natl Cancer Inst 2000, 92:205-216.

20. Common Toxicity Criteria version 3.0: National Cancer Institute; http://ctep. cancer.gov/reporting/ctc.html.

21. Akobeng AK: Understanding diagnostic tests 3: receiver operating characteristic curves. Acta Paediatr 2007, 96:644-647.

22. Cancer Staging Manual AJCC: 6th edition. Springer-Verlag New York: American Joint Committee on Cancer; 2002.

23. Milano MT, Katz AW, Muhs AG, Philip A, Buchholz DJ, Schell MC, Okunieff P. A prospective pilot study of curative-intent stereotactic body radiation therapy in patients with 5 or fewer oligometastatic lesions. Cancer 2008 112:650-658.

24. Brown W, Wu X, Fowler J, García S, Fayad F, Amendola BE, de la Zerda A Schwade JG: Lung metastases treated by CyberKnife image-guided robotic stereotactic radiosurgery at 41 months. South Med J 2008, 101:376-382.

25. Norihisa Y, Nagata Y, Takayama K, Matsuo Y, Sakamoto T, Sakamoto M, Mizowaki T, Yano S, Hiraoka M: Stereotactic body radiotherapy for oligometastatic lung tumors. Int J Radiat Oncol Biol Phys 2008, 72:398-403.

26. Rusthoven KE, Kavanagh BD, Burri SH, Chen C, Cardenes H, Chidel MA, Pugh TJ, Kane M, Gaspar LE, Schefte TE: Multi-institutional phase I/II trial of stereotactic body radiation therapy for lung metastases. J Clin Oncol 2009, 27:1579-1584.

27. Chi A, Liao ZX, Nguyen NP, Xu JH, Stea B, Komaki R: Systemic review of the patterns of failure following stereotactic body radiation therapy in early-stage non-small-cell lung cancer: clinical implications. Radiother Oncol 2010, 94:1-11. 
28. Haasbeek CJ, Lagerwaard FJ, de Jaeger K, Slotman BJ, Senan S: Outcomes of stereotactic radiotherapy for a new clinical stage I lung cancer arising postpneumonectomy. Cancer 2009, 115:587-594.

29. Senthi S, Haasbeek CJ, Lagerwaard FJ, Verbakel WF, de Haan PF, Slotman BJ, Senan S: Radiotherapy for a second primary lung cancer arising postpneumonectomy: planning considerations and clinical outcomes. J Thorac Dis 2013, 5:116-122.

30. Thompson R, Giuliani M, Yap ML, Atallah S, Le LW, Sun A, Brade A, Cho BCJ, Bezjak A, Hope A: Stereotactic body radiotherapy in patients with previous pneumonectomy: safety and efficacy. J Thorac Oncol 2014, 9:843-847.

31. Timmerman R, Paulus R, Galvin J, Michalski J, Straube W, Bradley J, Fakiris A, Bezjak A, Videtic G, Johnstone D, Fowler J, Gore E, Choy H: Stereotactic body radiation therapy for inoperable early stage lung cancer. JAMA 2010, 303:1070-1076.

32. Baumann P, Nyman J, Hoyer M, Gagliardi G, Lax I, Wennberg B, Drugge N, Ekberg L, Friesland S, Johansson KA, Lund JS, Morhed E, Nilsson K, Levin N, Paludan M, Sederholm C, Traberg A, Wittgren L, Lewensohn R: Stereotactic body radiotherapy for medically inoperable patients with stage I nonsmall cell lungcancerda first report of toxicity related to COPD/CVD in a nonrandomized prospective phase II study. Radiother Oncol 2008, 88:359-367.

33. Nagata Y, Hiraoka M, Shibata T, Onishi H, Kokubo M, Karasawa K, Shioyama Y, Onimaru R, Kunieda E, Ishikura S: A phase II trial of stereotactic body radiation therapy for operable T1N0M0 non-small cell lung cancer: Japan Clinical Oncology Group (JCOG0403). Int J Radiat Oncol Biol Phys 2010, 78:S27-S28.

34. Yamashita $H$, Nakagawa $K$, Nakamura $N$, Koyanagi $H$, Tago M, Igaki H, Shiraishi K, Sasano N, Ohtomo K: Exceptionally high incidence of symptomatic grade 2-5 radiation pneumonitis after stereotactic radiation therapy for lung tumors. Radiat Oncol 2007, 2:21.

35. Ricardi U, Filippi AR, Guarneri A, Giglioli FR, Mantovani C, Fiandra C, Anglesio $S$, Ragona R: Dosimetric predictors of radiation-induced lung injury in stereotactic body radiation therapy. Acta Oncol 2009, 48:571-577.

36. Borst GR, Ishikawa M, Nijkamp J, Hauptmann M, Shirato H, Onimaru R, van den Heuvel MM, Belderbos J, Lebesque JV, Sonke JJ: Radiation pneumonitis in patients treated for malignant pulmonary lesions with hypofractionated radiation therapy. Radiother Oncol 2009, 91:307-313.

37. Guckenberger M, Baier K, Polat B, Richter A, Krieger T, Wilbert J, Mueller G, Flentje M: Dose-response relationship for radiation-induced pneumonitis after pulmonary stereotactic body radiotherapy. Radiother Oncol 2010, 97:65-70.

38. Barriger RB, Forquer JA, Brabham JG, Andolino DL, Shapiro RH, Henderson MA, Johnstone PA, Fakiris AJ: A dose-volume analysis of radiation pneumonitis in non-small cell lung cancer patients treated with stereotactic body radiation therapy. Int J Radiat Oncol Biol Phys 2012, 82:457-462.

39. Ong CL, Palma D, Verbakel WFAR, Slotman BJ, Senan S: Treatment of large stage I-II lung tumors using stereotactic body radiotherapy (SBRT): Planning considerations and early toxicity. Radiother Oncol 2010, 97:431-436

40. Matsuo Y, Shibuya K, Nakamura M, Narabayashi M, Sakanaka K, Ueki N, Miyagi K, Norihisa Y, Mizowaki T, Nagata Y, Hiraoka M: Dose-volume metrics associated with radiation pneumonitis after stereotactic body radiation therapy for lung cancer. Int J Radiat Oncol Biol Phys 2012, 83:e545-e549.

41. Uno T, Isobe K, Kawakami H, Ueno N, Kawata T, Yamamoto S, Sekine Y, lyoda A, lizasa T, Fujisawa T, Shigematsu N, Ito H: Dose-volume factors predicting radiation pneumonitis in patients receiving salvage radiotherapy for postlobectomy locoregional recurrent non-small-cell lung cancer. Int J Clin Oncol 2006, 11:55-59.

42. Tucker SL, Jin H, Wei X, Martel MK, Komaki R, Liu HH, Mohan R, Chen Y, Cox JD, Liao Z: Impact of toxicity grade and scoring system on the relationship between mean lung dose and risk of radiation pneumonitis in a large cohort of patients with non-small cell lung cancer. Int J Radiat Oncol Biol Phys 2010, 77:691-698.

\section{doi:10.1186/1471-2407-14-719}

Cite this article as: Xiong et al: Stereotactic body radiation therapy for post-pulmonary lobectomy isolated lung metastasis of thoracic tumor: survival and side effects. BMC Cancer 2014 14:719.

\section{Submit your next manuscript to BioMed Central and take full advantage of:}

- Convenient online submission

- Thorough peer review

- No space constraints or color figure charges

- Immediate publication on acceptance

- Inclusion in PubMed, CAS, Scopus and Google Scholar

- Research which is freely available for redistribution 